\title{
Influence of Plasma-Induced Epoxy Coatings on the Interfacial Properties of Twaron/Epoxy Composites
}

\author{
Xiangyi Zhang ${ }^{1, a}$, Weiwei Men ${ }^{2, b}, \mathrm{Na} \mathrm{Ma}^{3, \mathrm{c}}$, Zhiqiang Wang ${ }^{4,}$ \\ ${ }^{1-4}$ Research Institute for Special Structures of Aeronautical Composites AVIC, The Aeronautical \\ Science Key Lab for High Performance Electromagnetic Windows, Ji'nan, Shandong, China, 250023 \\ a.zhangxy637@sina.com, b.weiweixm@163.com, c.mana12121985@163.com, \\ d.wangzhiqiang637@126.com
}

Keywords: Twaron fiber; plasma-induced coating; fiber surface; interfacial adhesion; SEM.

Abstract. This work deals with the oxygen-plasma-induced epoxy resin coating process on the surface of Twaron fiber in order to get a strong interfacial adhesion between the fibers and epoxy matrices. The influence of oxygen plasma treatment time on the surface morphologies and free energies of Twaron fibers and the interlaminar shear strength (ILSS), water absorption and fracture mechanisms of the composite were investigated. Surface chemical properties were studied by diffuse reflectance fourier transform infrared spectroscopy (FTIR). The fiber surface morphologies and wettability were analyzed by atomic force microscope (AFM) and dynamic contact angle analysis (DCAA), respectively. The interfacial adhesion performance of the Twaron fiber-reinforced epoxy composite was measured by ILSS and water absorption tests. The fracture mechanisms of composites were examined by scanning electron microscope (SEM).

\section{Introduction}

The continuous-fiber reinforced thermosetting resin matrix composites have been rapidly developed in recent years. The mechanical properties of polymer composites are dependent to a large extent on the reinforcing fiber[1-3]. The developed organic fibers, such as aramid fiber, poly(p-phenylene terephthalamide) (Twaron) fiber, has been widely used as reinforcement in advanced composites[4-6]. The aromatic ring structure contributes high thermal stability and chemical resistance; meanwhile the para configuration provides a rigid, rod-like polymer with high strength and modulus. Moreover, the aramid fiber was widely used in the area of electromagnetic windows due to its low dielectric properties. In a composite system, the high specific strength and modulus of the fiber are primary considerations but the functionality and texture of the fiber surface are very important in order to have a good adhesion to the matrix resin. The high specific tensile strength and modulus are the main advantage for Twaron fibers. However, the relative smooth surface and chemical inert of the fiber make the poor fiber/matrix adhesion properties, which reduce the potential in the applications in the composites[7].

Low-temperature plasma, excited by the electric fields, is an effective way on the surface modification with high efficiency and low energy consumption. The plasma treatment conditions are flexible and it brings no pollution, since few chemicals are involved. Plasma-induced coatings have been used to coat a polymeric size onto the fiber surface, which may contribute to the formation of an optimal bond[8-9]. Oxygen-plasma treatment could introduce $-\mathrm{OH} 、 \mathrm{O}=\mathrm{C}-\mathrm{O}$ groups onto the fiber surface and the oxygen-containing functional groups may improve the fiber surface polarity and its wettability[10]. Generally speaking, these oxygen-containing groups, such as $-\mathrm{OH}$, may have a chemical interaction with epoxy resin during the production process of composites[11]. Not only that, rougher morphologies of the surfaces of the fibers were obtained after plasma-induced coating, and the rougher surfaces may provide more contact area and improve the mechanical interlocking between the fiber and matrix. Therefore, a strong interfacial adhesion was occurred in the composite[12].

The study is focused on the influence of oxygen plasma treatment on the surface properties of Twaron fiber and the interfacial properties of Twaron/epoxy composite. The emphasis is put on the characterization of the surface morphologies, surface free energies and the interfacial properties of 
the composites. The surface chemical properties, surface morphologies and surface free energies were analyzed by diffuse reflectance fourier transform infrared spectroscopy (FTIR), atomic force microscopy (AFM) and dynamic contact angles (DCAA), respectively. The interfacial adhesion of the composite was evaluated by interlaminar shear strength (ILSS) and water absorption test. The fracture mechanism of the composite was examined by scanning electron microscope (SEM).

\section{Materials and methods}

Materials. Aramid fiber, poly (p-phenylene terephthalamide) (PPTA), was received as high modulus (HM, Twaron) yarn from Akzo Nobel Co. Ltd., Arnhem. The fibers were rolled on glass frames and cleaned consecutively with acetone and distilled water for $24 \mathrm{~h}$ each step at room temperature to remove surface sizing or finish. The fibers were then dried at $105^{\circ} \mathrm{C}$ in a vacuum oven for $3 \mathrm{~h}$ before plasma processing.

The epoxy resin was supplied by Nantong Xingchen Synthetic Material Co. Ltd, Jiangsu, China. The viscosity of the resin is $10000 \sim 16000 \mathrm{cPs} @ 25^{\circ} \mathrm{C}$ and the EEW is $184 \sim 195 \mathrm{~g} / \mathrm{mol}$. The curing agent was Anyhard 1010P and the catalyst was Anyhard 5050P. Both of the curing agent and catalyst were supplied by Shanghai Zhongsi Industry Co.,LTD, China.

Plasma treatment and composites preparation. The finish-removed Twaron fibers were put into a cylindrical processing chamber $(\Phi 30 \mathrm{~cm} \times \mathrm{H} 35 \mathrm{~cm})$ which connected to an energy source with excitation frequency of $13.56 \mathrm{MHz}$. The treatment parameters were as follows: the oxygen gas flow rate was $150 \mathrm{sccm}$ and the pressure was $30 \mathrm{~Pa}$, the input powers were $100 \mathrm{~W}$ and the exposure time was constant of $5,10,15$ and 20 min, respectively.

The freshly treated fibers were immediately soaked in the epoxy resin/ $\mathrm{CH}_{2} \mathrm{Cl}_{2}$ solution (with a concentration of $1.5 \mathrm{wt} \%$ ) for $12 \mathrm{~h}$ at a temperature of $25^{\circ} \mathrm{C}$. The coated fibers were impregnated with the epoxy resin system using a winding process at $85^{\circ} \mathrm{C}$ when the viscosity was relatively low. The coated epoxy resin was used without any curing agent. The Twaron fiber-reinforced epoxy composite was prepared by the compressing molding process, and the curing system was $120 \mathrm{~min}$ @ $80{ }^{\circ} \mathrm{C}+120 \min @ 120{ }^{\circ} \mathrm{C}$.

\section{Characterization}

FTIR. The relative amount of epoxy coatings on the Twaron fiber was examined by diffuse reflectance fourier transform infrared spectroscopy (FTIR) method. FTIR spectra were obtained in an NEXUS IR system which was manufactured in America. FTIR scans were performed in reflectance mode applying a wavenumber range of 2000-700 $\mathrm{cm}^{-1}$ with the wave-number resolution of $2 \mathrm{~cm}^{-1}$, and the average result of 32 automatic scans was output as the test result.

Surface morphology by AFM. The effects of plasma-induced coating on fiber surface morphology and surface roughness were analyzed by AFM in the tapping mode (Picoplus II, Agilent). A single fiber was fastened to a steel sample mount. Morphology images were simultaneously recorded for each fiber on various scanned areas $(4 \mu \mathrm{m} \times 4 \mu \mathrm{m})$. The surface roughness was evaluated by Rq, short for root mean-square, and $\mathrm{Ra}$, short for arithmetic mean roughness.

Contact angle and surface free energy measurements by DCAA. The total surface energy of a fiber can be determined using a two-liquid tensiometric method. The values of surface free energy of the uncoated and coated Twaron fibers were analyzed according to Wihelmy method on a dynamic contact angle analysis system (DCA-322, Thermo Cahn). The fiber sample was cut into about $1 \mathrm{~cm}$ in length and mounted indirectly to a wire hook suspending from microbalance and then immersed into the testing liquid media by elevating the stage at a constant speed of $1 \mathrm{~mm} / \mathrm{min}$. The contact angles $(\theta)$ were calculated using a computer system from Eq. (1).

$$
F=\gamma \cdot p \cdot \cos \theta
$$

where $\mathrm{F}$ is the wetting force between the fiber and the testing liquid, which is measured by the microbalance; $\gamma$ is the surface tension of the testing liquids; $p$ the wetted perimeter; $\theta$ the contact 
angle between fiber and liquid. Both advancing and receding dynamic contact angles $(\theta)$ were given during the test.

Various models have been proposed for the determination of the surface free energy from contact angle measurements. The main approximation is that the fiber surface free energy can be divided into two components: dispersive and polar. They were derived from Eqs. (2) and (3).

$$
\begin{gathered}
\gamma_{l}(1+\cos \theta)=2 \cdot \sqrt{\gamma_{s}^{p} \gamma_{l}^{p}}+2 \cdot \sqrt{\gamma_{s}^{d} \gamma_{l}^{d}} \\
\gamma_{\text {Total }}=\gamma_{s}^{p}+\gamma_{s}^{d}
\end{gathered}
$$

where $\gamma_{1}$ is the surface tension of the testing liquid, $\gamma_{\text {Total }}$ the surface free energy of the fiber, $\gamma_{\mathrm{s}}^{p}$ the polar component, and $\gamma_{s}^{d}$ the dispersive component. These two equations are so-called Owens-Wendt equation. According to Wu's approach, the contact angle could be related to two surface tension components. Thus, we used two testing liquids with different pole to be the testing liquids.

The testing liquids used in the measurement were water (polar solvent) and diiodomethane (nonpolar solvent), their surface tensions were $72.3 \mathrm{~mJ} / \mathrm{m}^{2}$ and $50.8 \mathrm{~mJ} / \mathrm{m}^{2}$, respectively.

Interfacial adhesion test by ILSS. ILSS was measured to estimate the interfacial adhesion strength of the composite. The ILSS data were obtained in a three-point short-beam bending test method on a Schimadzu universal testing machine according to JC/T 773-1996. The specimens were cut at the dimensions of $25 \times 6 \times 2 \mathrm{~mm}^{3}$, and the ratio of span to thickness was 5 . Each ILSS value was the average of five successful measurements. The specimens were tested at a constant cross-head movement rate of $2 \mathrm{~mm} / \mathrm{min}$. ILSS, $\tau$, was calculated according to the following expression:

$$
\tau=\frac{3 P_{b}}{4 b \bullet h}
$$

where $\tau$ is the interlaminar shear strength in $\mathrm{MPa}, \mathrm{P}_{\mathrm{b}}$ the maximum compression load at fracture in Newton, $b$ the width of the specimen in millimeters, and $h$ the thickness of the specimen in millimeters.

Water absorption test. The water absorption test was to investigate the interfacial properties of the Twaron fiber-reinforced epoxy composite. The experiment was carried out according to the ASTM D-570 method. Percentage of water absorption can be calculated to the nearest $0.01 \%$ as follows:

$$
\text { Water absorption }(\%)=\frac{m_{w}-m_{c}}{m_{w}} \times 100 \%
$$

where $\mathrm{m}_{\mathrm{w}}$ and $\mathrm{m}_{\mathrm{c}}$ stand for the wet weight and conditioned weight of the composite specimens, respectively.

Fracture mechanism analysis by SEM. In order to analyse the fracture mechanism of the composite, SEM (QUANTA 200, FEI) was applied to observe the mophologies of the shear ruptures of composite interlaminar. The chamber's pressure was evacuated to a pressure less than $60 \mathrm{~Pa}$ using a molecular pump. The fracture composite surfaces were examined and the magnification of the imagine for the composite interlaminar shear rupture was set at $1000 \times$.

\section{Results and discussion}

Surface chemical composition. In order to investigate the possible changes of chemical composition of the Twaron fibers before and after plasma-induced coating, FTIR spectroscopy measurements are performed. The left part of Fig.1, (a) was the untreated Twaron fiber, (b) was the oxygen-plasma-induced epoxy resin coated Twaron fiber (without extraction), (c) was the coated Twaron fibers with extraction. The right part of Fig.1, (a), (b) and (c) were the integral curves of the main characteristic peak. As shown in Fig. $1,1724 \mathrm{~cm}^{-1}$ is the absorption band of aromatic ester bond, which can be observed in (b) and (c). The results showed that the $\mathrm{C}=\mathrm{O}$ groups of the Twaron could 
have a chemical reaction with the epoxy groups. The $1032 \mathrm{~cm}^{-1}$ is the absorption band of aryl ether bond, which exists in the epoxy molecules. Both the coated samples, with and without extraction, existed the absorption band of aryl ether bond. On the contrast, the untreated sample was no such phenomenon. The results indicated that the epoxy resin was chemically grafted onto the fiber surface and then the aryl ether bond was appeared. We measured the relative residual functional band ratio to compare the characteristics of this system before and after treatment via Eq.6.

$$
\alpha=\frac{\frac{A_{914}}{A_{820(G 0)}}-\frac{A_{914}}{A_{820(G 1)}}}{\frac{A_{914}}{A_{820(G 0)}}-\frac{A_{914}}{A_{820(0)}}} \times 100 \%
$$

$\mathrm{A}_{914}$ is the area of the absorption band at $914 \mathrm{~cm}^{-1}, \mathrm{~A}_{820}$ represents the area of the absorption band at $820 \mathrm{~cm}^{-1}$ represented aromatic skeletal ring breathing vibration mode, which is not changed during

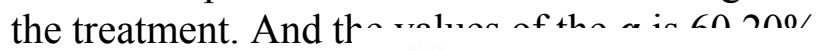

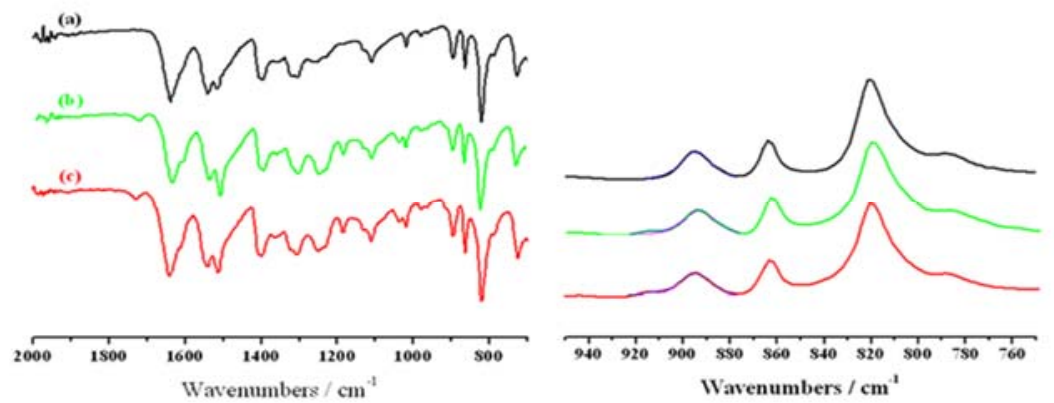

Fig.1. FTIR spectra of Twaron fibers before and after plasma-coated-epoxy modification.

These results clearly indicated that the plasma treatment could make the Twaron have an interaction with epoxy resin, and then a new polymeric layer was formed which could improve the adhesion between the fiber and matrix. Therefore, there were two interfaces in this case: one interface can be between the fiber and the epoxy resin while the other can be between the coated epoxy resin and the epoxy matrix. At the two interfaces, either primary or secondary bonds can exist between Twaron fiber and epoxy resin. These primary or secondary bondings may contribute to improving the interfacial adhesion.

Fiber surface morphology. Surface roughness of the reinforcement fibers has a remarkable influence on the interfacial adhesion properties of fiber and matrix [13]. Interface could be stronger with a complex fiber surface, because increasing surface roughness may change the mechanism of fracture mode of the composites. The effects of different plasma treatment time on the surface morphologies of Twaron fibers after coating by AFM were shown Fig. 2. It was found that the untreated Twaron fiber had a relatively smooth surface with only a few streaks. However, many prominences and grooves were visible on the surface after treatment, which can be seen in Fig.2 (b-e). Thus, it can be seen that the plasma-induced coating process could make the fiber surface tend to rougher, resulting from the etching effect of the plasma and the inhomogeneous of the coating layer. Therefore, the plasma-induced coated fiber surface had complicated structures, which may improve the physical interlocking between the fiber and matrix. 


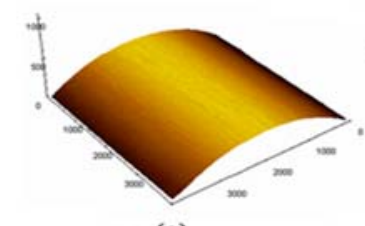

(a)
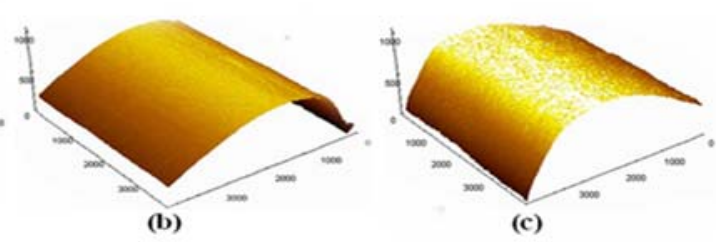

(c)

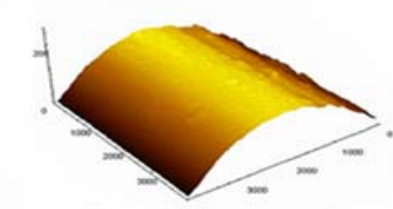

(d)

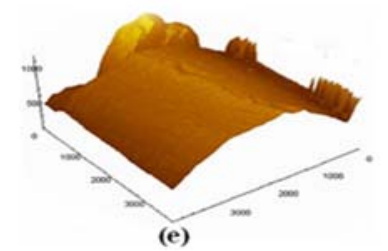

Fig. 2. AFM morphologies of Twaron fibers with different treat time: (a) untreated; (b) oxygen-plasma-treated 5 min; (c) oxygen-plasma-treated $10 \mathrm{~min}$; (d) oxygen-plasma-treated $15 \mathrm{~min}$; (e) oxygen-plasma-treated $20 \mathrm{~min}$.

Tab. 1 Surface roughness of epoxy-coated Twaron fiber with and without different oxygen-plasma treated time

\begin{tabular}{cccc}
\hline No. & Sample & $\mathrm{Rq}[\mathrm{nm}]$ & $\mathrm{Ra}[\mathrm{nm}]$ \\
\hline $\mathrm{a}$ & Untreated & 162.8 & 153.8 \\
$\mathrm{~b}$ & $\mathrm{O}_{2}$-plama treated for 5 min & 211.7 & 247.9 \\
c & $\mathrm{O}_{2}$-plama treated for 10 min & 261.8 & 212.8 \\
d & $\mathrm{O}_{2}$-plama treated for 15 min & 287.5 & 276.3 \\
e & $\mathrm{O}_{2}$-plama treated for 20 min & 331.5 & 289.6 \\
\hline
\end{tabular}

The roughness of fibers surface was evaluated with the Ra and $\mathrm{Rq}$ values, meaning arithmetic and root mean roughness, respectively. As shown in Table 1, the unsized fiber had lower $\mathrm{Rq}$ and $\mathrm{Ra}$ values of $162.8 \mathrm{~nm}$ and $153.8 \mathrm{~nm}$, respectively. After treatment, regardless of the treatment time, the fibers roughness increased comparing to the untreated sample, which agreed with the images above. The $\mathrm{Rq}$ and $\mathrm{Ra}$ values of the fiber surface after plasma treatment with a time of 5 min then coating were $211.7 \mathrm{~nm}$ and $247.9 \mathrm{~nm}$, respectively. With the treatment time increasing to 10, 15 and $20 \mathrm{~min}$, the surface roughness of the plasma-induced coated Twaron fibers kept increasing. The surface roughness of Twaron fibers enhanced almost linearly with the plasma treatment time increasing. When the fiber surface was subjected to plasmas, heavy collisions by charged species (ions and electron) with higher kinetic energy were unavoidable. The collisions gave rise to surface degradation of polymers and some polymer chains generated by the plasma could deposit on the fiber surface by absorption. With a long time plasma treatment, the fiber surface existed many active atoms and groups, which may have much more effect with the epoxy resin.

The greater roughness could increase contact area between the fiber and the matrix and thereby contributed to a higher degree of their mechanical interlocking. The coating layer was nonuniform and most of the epoxy resins were still small molecules before compression molding. Hence, the matrix molecules may dive into the epoxy coating layers during the solution impregnation. Therefore, the coating layer acted as a bridge between the fibers and the matrices.

Fiber surface free energy. Surface free energy of the Twaron fiber was determined by the dynamic contact angle analysis. It is deemed to be a strong gage of solid surface and adhesion strength between fibers and matrix. Generally, better wetting can enhance the interfacial adhesion by introducing more polar groups and an uneven fiber surface to improve the work of adhesion. In contrary, incomplete wetting may reduce the adhesion strength[13]. It is well known that fibre wettability is the characterization of surface free energy which includes polar and dispersive components[14]. The surface free energy was analyzed from the measured contact angles which were obtained from each fiber sample contacted with two different liquids in our experiments. The surface energy components of the two testing liquids including distilled water and diiodomethane are $72.3 \mathrm{~mJ} / \mathrm{m}^{2}$ and $50.8 \mathrm{~mJ} / \mathrm{m}^{2}$, respectively. The surface wettability of fibers untreated and plasma-coated was examined by DCAA. The measured contact angles and the derived surface free energy of untreated and coated fibers were shown in Table 2. The standard deviations are also given in the table and each data entry is the average of five or more measurements. 
The advancing contact angles of water declined by degrees from $67.8^{\circ}$ for the untreated sample to $42.6^{\circ}$ for the plasma-induced coated with a treatment time of $10 \mathrm{~min}$. When the treatment time was 5 min, the contact angle of water was $58.3^{\circ}$. However, after the oxygen treatment time for 15 min and $20 \mathrm{~min}$, the contact angles of water on Twaron fibers increased to $48.2^{\circ}$ and $53.7^{\circ}$. Accordingly, the polar components of the free energies were changed from $9.3 \mathrm{~mJ} / \mathrm{m}^{2}$ for the untreated sample to 22.8 $\mathrm{mJ} / \mathrm{m}^{2}$ for the treatment time was $5 \mathrm{~min}, 24.0 \mathrm{~mJ} / \mathrm{m}^{2}$ for $10 \mathrm{~min}, 20.4 \mathrm{~mJ} / \mathrm{m}^{2}$ for $15 \mathrm{~min}$ and 17.6 $\mathrm{mJ} / \mathrm{m}^{2}$ for $20 \mathrm{~min}$, respectively. The changes of the dispersive component of surface free energies are not distinct. The total free energies were changed from $49.9 \mathrm{~mJ} / \mathrm{m}^{2}$ for untreated sample to 61.9 $\mathrm{mJ} / \mathrm{m}^{2}$ for the plasma treatment was $5 \mathrm{~min}, 62.7 \mathrm{~mJ} / \mathrm{m}^{2}$ for $10 \mathrm{~min}, 60.0 \mathrm{~mJ} / \mathrm{m}^{2}$ for $15 \mathrm{~min}$ and 56.0 $\mathrm{mJ} / \mathrm{m}^{2}$ for $20 \mathrm{~min}$. The results were consistent with the AFM results.

Tab.2 Contact angles and surface free energies of the Twaron fibers

\begin{tabular}{cccccc}
\hline \multirow{2}{*}{ Samples } & \multicolumn{2}{c}{ Contact angles $(\theta) \pm$ s.d. $\left[^{\circ}\right]$} & \multicolumn{2}{c}{$\begin{array}{c}\text { Surface free energy } \\
{\left[\mathrm{mJ} / \mathrm{m}^{2}\right]}\end{array}$} \\
\cline { 2 - 6 } & Water & Diiodomethane & $\gamma^{p}$ & $\gamma^{d}$ & $\gamma^{\mathrm{T}}$ \\
\cline { 2 - 6 } & $67.8(2.6)$ & $37.9(2.9)$ & 9.3 & 40.6 & 49.9 \\
Untreated & $58.3(1.7)$ & $41.1(1.3)$ & 22.8 & 39.1 & 61.9 \\
Plasma-treated for 5 min & $42.6(1.8)$ & $41.7(1.4)$ & 24.0 & 38.7 & 62.7 \\
Plasma-treated for 10 min & $48.2(2.0)$ & $40.1(2.3)$ & 20.4 & 39.6 & 60.0 \\
Plasma-treated for 15 min & $53.7(1.2)$ & $42.3(1.9)$ & 17.6 & 38.4 & 56.0 \\
Plasma-treated for 20 min & &
\end{tabular}

Standard deviations are in parentheses.

According to Wenzel[15], the wettability improved not only with the introduction of polar groups, but also with the surface roughness of solids while the contact angles were less than $90^{\circ}$. Combined with the FTIR and AFM results, it can be inferred that surface roughening occurs, and together with polar functionalities generated in the treatment. Both factors are thought to contribute to the interfacial adhesion[16].

Composite ILSS. The Twaron fiber-reinforced polymer composites exhibited poor engineering properties due to the fibers' smooth and inert surfaces. It is well known that the interface is an important factor for stress transferring from the matrix to the fiber and good engineering properties of the composites were largely dominated by the nature of the interface. The coating resin was the major component of the interface in a composite. In other words, the interlaminar shear strength can be used to predict the efficiency of the coating in a composite. The mechanical properties of the interface are characterized by the interlaminar shear strength of the composite.

Table 3 showed the influence of treatment time on the ILSS values of Twaron/epoxy composite. The untreated sample exhibited a lowest value of $69.2 \mathrm{MPa}$. After plasma-induced coating process, the ILSS values of the composites increased. When the treatment time was $10 \mathrm{~min}$, the ILSS got a highest value of $97.1 \mathrm{MPa}$, with an increment of $40.3 \%$. However, when the treatment time were $15 \mathrm{~min}$ and $20 \mathrm{~min}$, the ILSS values were decreased. The fiber surface might undergo excessive chemical and/or physical reactions with the long-time plasma treatment.

Tab.3. Effects of oxygen-plasma treat time on ILSS of Twaron/epoxy composites.

\begin{tabular}{cccccc}
\hline Treatment time $[\mathrm{min}]$ & 0 & 5 & 10 & 15 & 20 \\
\hline ILSS $[\mathrm{MPa}]$ & $69.2(0.07)$ & $81.5(0.03)$ & $97.1(0.05)$ & $92.6(0.04)$ & $84.1(0.03)$ \\
\hline
\end{tabular}

Standard deviations are in parentheses.

After coating, the chemical composition and morphologies of the fiber surfaces had a great change. The improvement might be caused by the mechanical interlocking and the diffusion of the polymer molecules. To sum up, the plasma-induced epoxy coating was an effective way to improve the interfacial adhesion of the Twaron/epoxy composite. 
Composite humid resistance property. Water absorption testing was also selected to estimate the interfacial adhesion of Twaron fiber reinforced epoxy composite. The effects of plasma treatment time on the coated Twaron fiber/epoxy composite could be found in Fig. 3. In the case of untreated sample, its composite had a higher value of water absorption being $0.85 \%$ because of the poor interfacial adhesion between the fiber and matrix. As for the plasma-induced-coated samples with different treatment time, such as $5 \mathrm{~min}, 10 \mathrm{~min}, 15 \mathrm{~min}, 20 \mathrm{~min}$, the water absorptions were $0.47 \%$, $0.38 \%, 0.56 \%$ and $0.61 \%$, respectively. The results revealed that the interfacial adhesion was enhanced and the voids in the interface were reduced after coating. The lowest value was existed while the plasma treatment tim..... $1 \mathrm{n}$ min

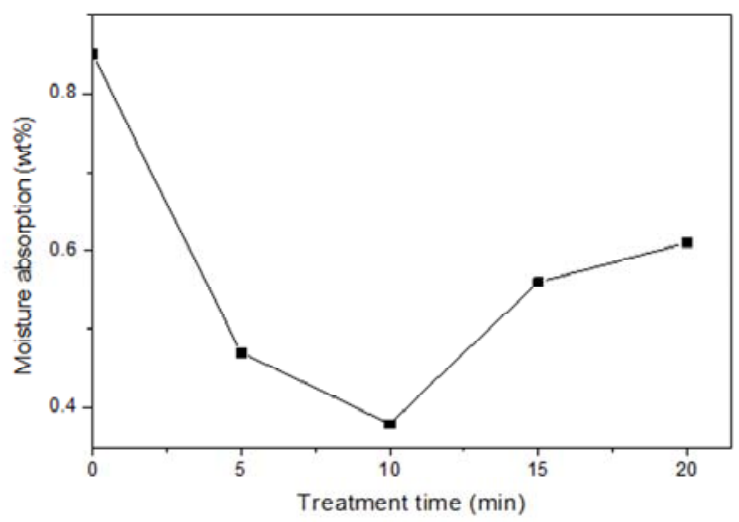

Fig. 3. Effects of oxygen-plasma treat time on water absorption of Twaron/epoxy composites.

The subsequent increase in water absorption could be attributed to the undue plasma treatment condition. Combined with the results of AFM, when the discharge time was more than $10 \mathrm{~min}$, the fiber surfaces were tough irregular, which may introduce much more voids at the interface between the fiber and matrix. Therefore, the water could easily diffuse into the composite. Both of the ILSS and water absorption tests arrived at the same conclusion. Excessive plasma treatment could reduce the properties of the interface of a composite.

Composite fracture mechanism. When composite suffers from load, the failure mechanisms of a composite satisfy the Kelly-Tyson theory[17-18]. When interfacial adhesion is strong, destruction of the composite will take place in matrix near the interface, with resin adhesive on fiber surface; conversely, the interfacial adhesion is weak, fibers will be peeled off from matrix, and the fiber is clean, with little resin adhesive on the surface. Therefore, the fracture morphology of the composite after delamination can give us visual information about the interfacial adhesion characteristic.

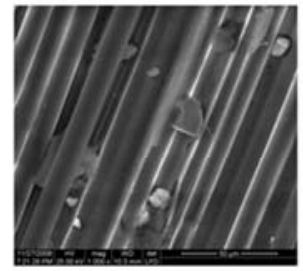

(a)

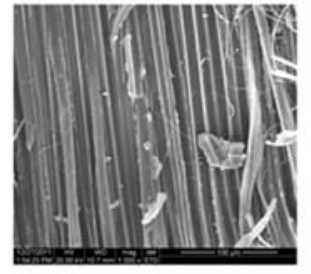

(b)

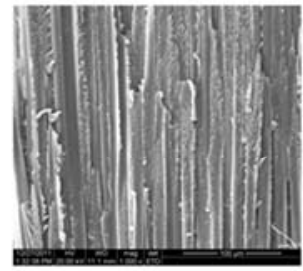

(c)

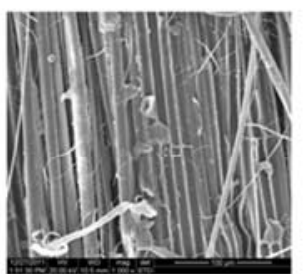

(d)

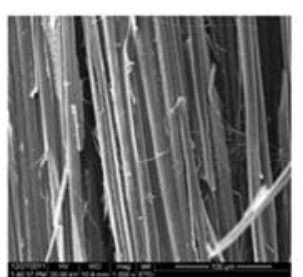

(e)

Fig.4. Effects of oxygen-plasma treated time on fractured morphologies of Twaron/epoxy composite (a) untread; (b) oxygen-plasma-treated 5 min;(c) oxygen-plasma-treated $10 \mathrm{~min}$;(d) oxygen-plasma-treated 15 min;(e) oxygen-plasma-treated $20 \mathrm{~min}$.

As shown in Fig.4, the fibers for the untreated composite were smooth with little resin adhering to them, indicating that the interfacial adhesion was weak and the fiber/resin debonded first; after 
plasma-induced coating, many resin fragments still adhered to the fibers, suggesting that the primary failure occurred in the matrix. The interfacial adhesion for the coated composite was obviously better than that for the untreated sample. The improved interfacial adhesion could effectively transfer the stress from the matrix to the Twaron fiber; therefore the mechanical performance of the Twaron/epoxy composites in considerably improved.

The SEM results revealed that the plasma-induced coating was an effective method to improve the interfacial adhesion. These results were in qualitative agreement with the ILSS and humid resistance results.

\section{Conclusions}

In this study, oxygen plasma was employed to induce the epoxy resin coated onto the Twaron fiber surface in order to enhance the interfacial adhesion between the fiber and the matrix. The FTIR results showed that amount of the epoxy resin had a strong interaction with the Twaron fiber induced by the plasma. The AFM tests showed that the coating process could change the surface morphologies and roughness of the Twaron fiber, and the fiber surfaces became more complicated with the extension of treatment time. The ILSS and water absorption measurements of Twaron fiber-reinforced epoxy composite indicated that the interfacial adhesion of the composite was largely improved by plasma-induced coating process. Fracture SEM images of Twaron/epoxy composites showed that the interfacial adhesion of oxygen-plasma-induced coated Twaron fiber-reinforced epoxy composite was better than the untreated sample, the primary failure modes were changed from interface debonding to matrix fracture.

\section{References}

[1] W-Y. Yeh, R.J.Young, Polymer, 1999, 40, 857.

[2] John Summerscales, Nilmini P.J.Dissanayake, Amandeep S. Virk, Wayre Hall, Composites: Part A. 2010, 41, 1329.

[3] Leif A Crlsson, Thermoplastic Composite Materials, 1991, Elsevier: Newyork.

[4] A.B.David, P. Gerald, D.Yves, J. Appl. Polym. Sci. 1993, 47, 883.

[5] L. Liu, Y.D. Huang, Z.Q. Zhang, Z.X. Jiang, L.N. Wu, Appl.Surf. Sci 2008, 254, 2594.

[6] P.J. de Lange, E. Mader, K. Mai, R.J. Young, I. Ahmad, Compos. Part A 2001, 32, 331.

[7] L.T.Drzal, M.Madhukar, J. Mater. Sci 1993, 28, 569.

[8] Xiangyi Zhang, Ping Chen, Xiaotao Kang, Mingxin Chen, J.Appl.Polym.Sci 2012,123, 2945.

[9] Xiangyi Zhang, Ping Chen, Debin Han, Qi Yu, Zhenfeng Ding, Appl. Surf. Sci. 2013, 266, 110.

[10] Caixia Jia, Ping Chen, Wei Liu, Bin Li, Qian Wang, Appl. Surf. Sci 2011, 257, 4165.

[11] Xiangyi Zhang, Ping Chen, Qi Yu, Keming Ma, Zhenfeng Ding, Xiuling Zhu, Vacuum, 2013, $97,1$.

[12] B. Song, L.H. Meng, Y.D.Huang, Applied Surface Science, 2012, 258, 10159.

[13] D. Liu, J. Hu, Y. Zhao, X. Zhou, P. Ning, Y. Wang, J. Appl. Polym. Sci 2006, 102, 1428.

[14] C. Lu, P. Chen, Q. Yu, Z.F. Ding, Z.W. Lin, W. Li, J. Appl. Polym. Sci. 2007, 106, 1733.

[15] P. Chen, C. Lu, Q. Yu, Y. Gao, J.F. Li, X.L. Li, J.Appl.Polym.Sci 2006, 102, 2544.

[16] R.N. Wenzel, Ind. Eng. Chem 1936, 28, 988.

[17] Vlasveld D.P.N, Parlevliet, P.P., Bersee H.E.N., Compos. Part A 2005, 36, 1.

[18] Ye L, Afaghi-Khatibi A, Lawcock G, Compos. Part A 1998, 29, 1525. 